\title{
Has the Reform of the Administrative Examination and Approval System Increased the Efficiency of Resource Allocation: Evidence from China
}

\author{
Yangyang Zhong, ${ }^{1}$ Yilin Zhong, ${ }^{2}$ and Longpeng Zhang $\mathbb{D}^{3}$ \\ ${ }^{1}$ School of Marxism, University of Electronic Science and Technology of China, Chengdu 611731, China \\ ${ }^{2}$ School of Economic and Finance, South China University of Technology, Guangzhou 510405, China \\ ${ }^{3}$ School of Public Affairs and Administration, University of Electronic Science and Technology of China, Chengdu 611731, China
}

Correspondence should be addressed to Longpeng Zhang; zlp1988@uestc.edu.cn

Received 16 September 2020; Revised 30 November 2020; Accepted 28 December 2020; Published 8 January 2021

Academic Editor: Haoran Zhang

Copyright (c) 2021 Yangyang Zhong et al. This is an open access article distributed under the Creative Commons Attribution License, which permits unrestricted use, distribution, and reproduction in any medium, provided the original work is properly cited.

\begin{abstract}
Based on data from the China Industry Business Performance Database from 1998 to 2007 and the time of establishment of the administrative examination and approval center in each administrative division in China, this study attempts to empirically determine the effects of the reform of the administrative examination and approval system on the efficiency of resource allocation from the perspectives of the degree of enterprise-level productivity dispersion. The empirical results showed that the reform of the administrative examination and approval system significantly reduced the degree of productivity dispersion among enterprises in an industry, in addition to enhancing the efficiency of resource allocation in the industry. A further analysis of heterogeneity revealed that the reform of the administrative examination and approval system yielded greater enhancements of the efficiency of resource allocation in industries with lower entry and exit rates.
\end{abstract}

\section{Introduction}

The efficiency of resource allocation is not only an important determinant of the existing gap between the productivity and income levels of different economies [1-3] it is also a key factor that influences a country's economic growth [4]. As a result, there has been an increase in the number of studies on the factors influencing the efficiency of resource allocation, with the goal of achieving an optimal allocation of resources and, thereby, increasing the total factor productivity of an economy. In a perfect market, an inefficient enterprise will exit the market due to natural selection, and its former resources will be reallocated to efficient enterprises, thereby increasing the efficiency of resource allocation [5]. However, if market mechanisms become distorted, an inefficient enterprise will remain in the market and continue to occupy a portion of resources, thereby distorting the process of resource allocation and causing resource misallocation. There are a multitude of institutional factors impeding the development of market mechanisms in countries with different types of economic systems. Consequently, the efficiency of resource allocation is reduced. Government regulation or government intervention is one of the key factors that reduce the efficiency of resource allocation [6].

Researchers agree that a relatively serious resource misallocation effect exists in China, as the factors of production are not effectively allocated among enterprises $[2,7,8]$. Government regulation or intervention factors such as the hukou (household registration) system, localism, government subsidies, and credit policies have systematically reduced the efficiency of the allocation of China's resources. Hsieh and Klenow [2] pointed out that China's reform of factors hindering the efficient allocation of resources in its economic system had significantly enhanced its economic output. On this basis, the Chinese government has implemented a series of institutional reforms with the goals 
of increasing the efficiency of resource allocation, unleashing China's economic development potential, reducing the impacts of government interventions on the economy, and stimulating the resource allocation function of market mechanisms.

China's reform of its administrative examination and approval system is one of the most crucial measures in this series of institutional reforms. The administrative examination and approval system reform was intended to clarify the boundaries between the government and the market by easing regulations and reducing government intervention, thus realizing the market's decisive role in economic development. According to the hypotheses proposed by the two competing theories of public interest theory and public choice theory, government regulations have positive and negative effects on an economy. In public interest theory, government regulations can remedy market failures and produce optimal social outcomes [9]. Strict regulations play the role of screening new enterprises so as to select enterprises that are able to provide high quality goods or services. On the other hand, public choice theory argues that strict government regulations are a hindrance to market entry, thus reducing market competitiveness and enhancing the interests of those in power [10-12]. Moreover, government regulations are regarded as rent-seeking tools used by politicians and officials against market entrants [13]. Therefore, this study sought to resolve the issue of whether the efficiency of resource allocation can be enhanced by the reform of the administrative examination and approval system, which centers on easing regulations and reducing government intervention.

Section 2 provides a review of the literature; Section 3 provides an analysis of institutional backgrounds and theories; Section 4 introduces the data sources, econometric models, and measurement of variables; Section 5 offers empirical validation methods which consist of regression analyses and robustness tests; Section 6 further analyses the heterogeneity of the effects of the reform on the efficiency of resource allocation; and Section 7 provides the conclusions of this research.

\section{Literature Review}

This research is closely related to two fields of study. One field consists of studies on the economic effects of government regulatory reforms, while another consists of studies on the factors governing the efficiency of resource allocation. The authors have organized and summarized the two types of studies so as to clarify the academic contributions of the current study.

2.1. Review of Literature on the Economic Effects of Government Regulatory Reforms. Many scholars have performed comprehensive and in-depth assessments of the economic effects of the government regulatory reforms. In particular, the study by Djankov et al. [14] has great importance. They investigated the time and cost spent by start-up companies in 85 countries in 1999 to meet all governmental requirements. This served as the basis for measuring a country's regulation of entry. The study indicated that a stricter regulation of entry will generate greater corruption and larger informal economies in addition to not providing goods or services with better qualities. Since then, many studies have examined the economic effects of regulation of entry reforms. A multitude of scholars, such as Branstetter et al. [15], Bruhn [16], Kaplan et al. [17], and RostamAfschar [18], have studied the effects of regulatory reforms on market entry. The results indicated that easing regulations facilitates market entry and encourages economic and employment growth. Schivardi and Viviano [19] studied the sectoral performance of the regulations of entry reform of the Italian retail trade industry in 1998. Furthermore, the economic effects of other regulatory reforms have received much attention. The studies by Black and Strahan [20], Lee et al. [21], and Nystrom [22] revealed that deregulatory measures in the banking industry, job market, and enterprise bankruptcy had effectively enhanced the viability of market entry. Casu et al. [23] studied the effects of postfinancial crisis regulatory reforms in Asian countries on the performance of the banking industry. Their empirical results supported the positive effects of the easing of regulations on the banking industry. Guerrini et al. [24] evaluated the impacts of regulatory reforms in the Italian water sector on the performance of water utilities. The results showed that the positive effects of the reforms in the water utilities sector were limited.

In general, the studies discussed above suggest that government regulatory reforms can generate positive economic effects to a certain extent. Strict regulations are not socially optimal, an outcome that supports public choice theory. However, these studies merely evaluated the economic effects of government regulations in a certain sector and did not evaluate the economic impacts generated by overall government regulations. As a result, the assessment results are restricted to a certain extent, whereas China's reform of the administrative examination and approval system was centered on a comprehensive reform and easing of government regulations. Therefore, China's reform of the administrative examination and approval system can be used to conduct a comprehensive assessment of the economic effects of government regulation reforms.

2.2. Review of Literature on Factors Governing the Efficiency of Resource Allocation. On the basis of measuring the efficiency of resource allocation, scholars have explored the key factors affecting the efficiency of resource allocation from different perspectives. Balasubramanian and Sivadasan [25] assessed the impacts of sunk costs on the efficiency of resource allocation. Their results revealed that reducing sunk costs can reduce industry concentration while significantly increasing the allocative efficiency of enterprises in an industry. Guner et al. [26] observed the resource misallocation effects generated by policies dependent on enterprise size. The results suggested that tax policies and employment protection are vitally dependent on enterprise size, as effective tax rates and effective protection rates can reflect the 
characteristics of enterprise size dependence. Ding et al. [27] studied the effects of free trade on the efficiency of resource allocation. They reported that import penetration achieves a dynamic adjustment of intraindustry resources through competition and promotes inefficient enterprises to exit the market, thereby elevating the efficiency of resource allocation. In recent years, a batch of scholars has turned their attention to the spatial allocation of resources. Based on the perspectives of real estate supply restrictions and tax competition, these scholars sought to determine the factors of spatial misallocation of resources. Desmet and RossiHansberg [28] divided market size into three components: efficiency, amenities, and friction. On this basis, they verified that reducing friction within cities can lead to a spatial reallocation of population resources, thereby increasing welfare levels. Brandt et al. [7] utilized China's database to explore the intraprovincial and interprovincial distortion of labor resources and output losses. Their results delineate a significant declining trend in the misallocation of labor resources in the intraprovincial level. However, the misallocation of resources in the interprovincial level did not improve. Hsieh and Moretti's [29] study revealed that a large wage gap exists between American cities, as real estate supply restrictions had limited the expansion of efficient cities, which ultimately results in the spatial misallocation of American resources and production losses. Based on the perspectives of tax rates in different American states, Fajgelbaum et al. [30] identified the spatial misallocation of resources and corresponding production losses generated by the regional differences in tax rates.

Based on the existing literature, even though institutional distortion is an important factor of resource misallocation, the effects of institutional reforms on the efficiency of resource allocation are worth discussing. Regretfully, studies on the factors governing the efficiency of resource allocation or the performance evaluation of regulatory reforms have not investigated the impacts of the administrative examination and approval system reform on the efficiency of resource allocation. In view of this gap in the existing literature, this study performed an empirical evaluation of the impacts of the administrative examination and approval system reform on the efficiency of resource allocation.

\section{Institutional Background and Theoretical Analysis}

3.1. Institutional Background. In a planned economy, the government is the sole entity controlling the activities in the economy or society. Hence, the administrative examination and approval system is China's key approach to maintaining the stability of the social order, guaranteeing the successful implementation of mandatory plans, and ensuring the rational allocation of limited resources. Since 1992, China's economic system has transformed from a socialist planned economy to a market economy. A large shift in an economic system must require government institutional reforms to comply with it. The administrative examination and approval system under a planned economy is no longer able to adapt to the development needs of a socialist market economy. Therefore, the reform of the administrative examination and approval system is a crucial approach for standardizing and optimizing the relationship between the government and the market. The reform of China's administrative examination and approval system first began in the open coastal cities of Shenzhen and Jiangmen. The reform came into effect on a nationwide level after China had joined the World Trade Organization (WTO) in 2001, and the General Office of the State Council had issued the Notice on the Establishment of the State Council Leading Group for the Reform of the Administrative Examination and Approval System. More specifically, the reform of China's administrative examination and approval system has consisted of three phases from 2001 to the present.

3.1.1. Phase 1 (2001-2004). This phase consisted primarily of institutional developments implemented to stimulate market vitality. Reforms in this phase aimed to reduce administrative restrictions, open up the market, and promote market vitality. Many invalid and inefficient administrative examination and approval items were either omitted or adjusted, and the Advice on Implementing the Reform of the Administrative Examination and Approval System was introduced.

3.1.2. Phase II (2004-2013). This phase involved the implementation and standardization of government-enterprise relations. Following the promulgation of the Administrative Law of the People's Republic of China in 2004, the Notice on the Further Cancellation and Adjustment of the Administrative Examination and Approval Items in 2007, and the Notice on Deepening the Reform of the Administrative Examination and Approval System in 2008, the administrative examination and approval system became legalized and standardized, thereby effectively promoting the realization of market mechanisms and reducing rentseeking opportunities.

3.1.3. Phase III (2013-Present). Based on the core principle of "streamline administration, delegate power, strengthen regulation, and improve service," this phase aims to deepen and innovate the reform. This stage places an emphasis on clarifying government-market relations and realizing the determinant function of the market in resource allocation. Major restrictions were imposed on government intervention on enterprise operation, and the scope of administrative examination and approval was largely reduced. In 2016, the State Council promulgated the Guiding Opinions on Accelerating the Promotion of the "Internet + Government Services" Work, which stressed the integration of online and offline reforms. This signified an important transformation in the reform of China's administrative examination and approval system. Between 2013 to 2018, 44\% of the 1700-plus administrative examination and approval items established from the previous regime for State Council departments were omitted, leaving 900-plus items for administrative 
approval and bringing an end to nonadministrative licensing examination and approval.

Prior to the reform, the authority for administrative examination and approval was dispersed among various functional departments. This meant that many items had to be examined and approved repeatedly and many forms had to be filled out repeatedly. As a result, the general public had to go through repeated procedures for a single administrative examination and approval application, and this greatly reduced their satisfaction. In order to comply with the requirements of the reform, decentralize the authority for administration examination and approval, and further integrate and optimize the process of the reform, administrative examination and approval centers were established in various locations. These centers enabled the dispersed functional departments to complete their examination and approval duties in a centralized "one-stop" location that offers joint and integrated services. This approach not only saved time and reduced costs for administrative examination and approval but also enhanced the quality of services provided to the public. In addition, the transparency of administrative examination and approval was increased, which prevents rent-seeking operations. In other words, the establishment of administrative examination and approval centers by regional governments is an important step in the implementation of China's administrative examination and approval system reform.

In 1995, Shenzhen became the first city to set up an administrative examination and approval pilot center. From 2001 onwards, the nationwide promotion of the reform caused establishment administrative examination and approval centers to be set up in multiple locations. Figure 1 shows the distribution of the time of establishment of administrative examination and approval centers in Chinese cities. From the figure, it can be seen that the establishment of the centers peaked during 2001 to 2002. After 2002, the number of newly established prefecture-level administrative examination and approval centers declined annually. As of 2015, 316 Chinese cities have established administrative examination and approval centers, accounting for $94.9 \%$ of the total number of cities in China. Hence, the administrative examination and approval center can be regarded as an important agent for China's reform of its administrative examination and approval system.

3.2. Theoretical Analysis. Resource allocation refers to the distribution of factors of production, such as capital and labor, among enterprises. When resources flow from an enterprise with low efficiency to one with high efficiency, the optimal allocation of resources is achieved, thereby promoting a growth in total factor productivity. An important premise for optimal resource allocation and enhanced allocative efficiency is the unrestricted flow of resources. If the flow of resources becomes obstructed, the factors of production are unable to flow from inefficient enterprises to efficient enterprises. Hence, market entry and exit mechanisms must be ideal to allow the unrestricted flow of resources. If an efficient enterprise is unable to enter a market while an inefficient enterprise is unable to exit a market, the latter will continue to occupy a share of production resources and the former will not be able to access these resources. Therefore, market entry and exit are crucial for the allocation of resources.

Government regulation or intervention happens to be an important factor behind a decline in the efficiency of resource allocation [6]. The efficiency of resource allocation in an economy can be improved effectively by easing up government regulations and standardizing government actions. Hence, the administrative examination and approval reform is an important measure for changing governmental functions since it clarifies government-market relations and realizes the function of the market as a determinant for resource allocation. Thus, the reform could generate important effects on the efficiency of resource allocation. From the perspectives of market entry and exit, this study sought to delineate the mechanisms of the administrative examination and approval system reform affecting the efficiency of resource allocation.

Based on the views of market entry, the reform of the administrative examination and approval system aims to reduce enterprise start-up time and cost through an integration and optimization of administrative procedures and removal of minimum paid-in capital. As a result, the business start-up requirements are lowered, which, in turn, boosted start-up plans among Chinese citizens and increased the number of new establishments [17, 18]. The market entry of an enterprise achieves optimal resource allocation through two methods: market selection and learning effects [31, 32]. In the former, new enterprises are able to eliminate low-performing existing enterprises through market selection, thus obtaining the resources previously occupied by the inefficient enterprises. In the latter, new enterprises will maintain their accelerated growth through learning and continue to attract the flow of resources. Therefore, the reform of the administrative examination and approval system achieves the optimization of resource allocation by lowering market entry requirements.

A zombie company refers to an inefficient company that has failed to achieve consistent profitability but still refuses to exit the market [33]. A large number of zombie companies in an economy will create a multitude of negative impacts on economic development [34]. If a zombie company is unable to exit the market in a timely manner, it will continue to occupy a larger share of production resources and obstruct the flow of factors of production from enterprises with low productivity and return to those with high productivity and return. This is detrimental for the reallocation of production resources. Zombie companies are formed by numerous factors such as credit subsidies, loan extensions, and lowinterest loans offered by banks to inefficient companies $[33,35,36]$, as well as government intervention [34]. Low product quality, inadequate technological innovation, and lack of entrepreneurial spirit are all important microfactors influencing the creation of zombie companies. The reform of the administrative examination and approval system implies the streamlining of examination and approval procedures, 


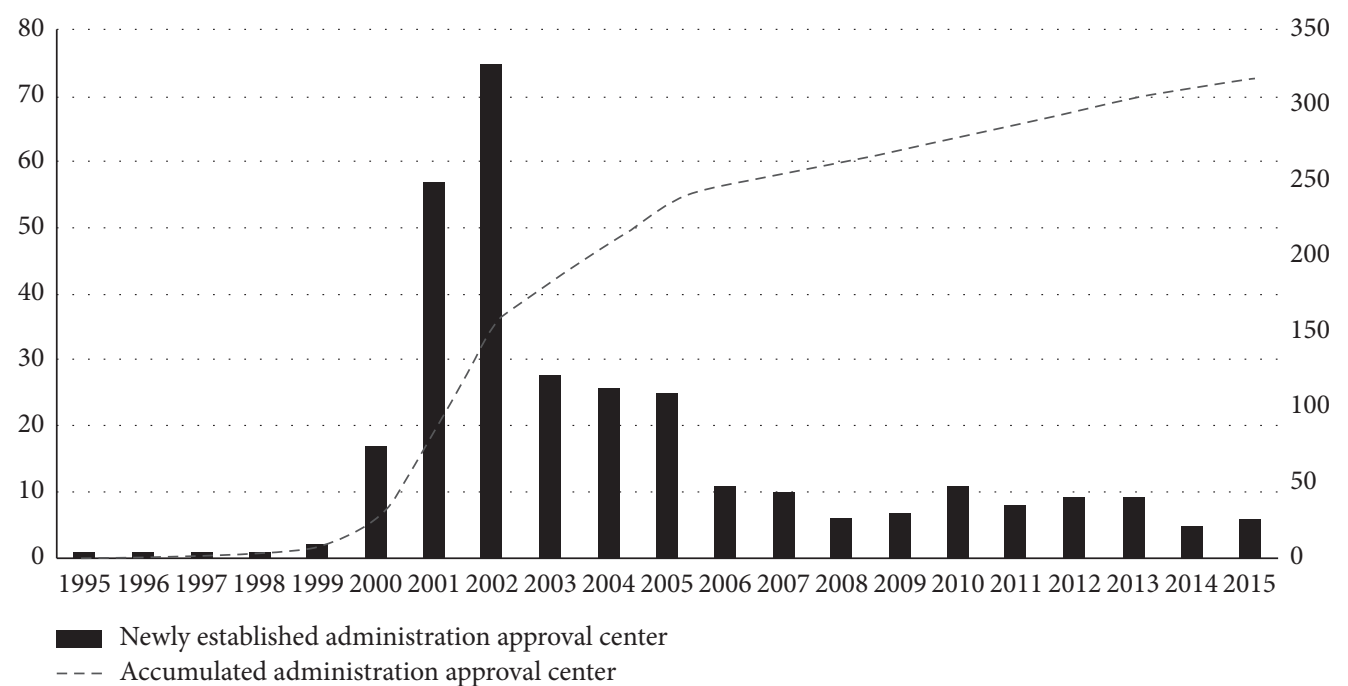

FIGURE 1: Distribution of the time of establishment of administrative examination and approval centers in Chinese cities.

decentralization of items, and integration of services so as to reduce rent-seeking activities caused by administrative examination and approval, lower institutional transaction costs, stimulate the entrepreneurial spirit of productive companies, increase enterprise innovation, and prevent companies from turning into zombie companies. Therefore, the reform is able to prevent the formation of zombie companies, thereby reducing the number of inefficient enterprises in the market and their possibility of resource occupancy, as well as enhancing the efficiency of resource allocation.

Based on the analysis above, the hypothesis of this study can be deduced. The reform of the administrative examination and approval system was able to enhance the efficiency of resource allocation by correcting market entry and exit mechanisms.

\section{Research Design}

4.1. Data Sources. The data in this study were obtained from the China Industry Business Performance Database from 1998 to 2007. The database offers details on Chinese stateowned enterprises and sizable nonstate-owned enterprises (with a sales revenue of over CNY¥5 million). The statistical indexes of the China Industry Business Performance Database consist of basic enterprise attributes (type of registration, number of employees, type of industry, geographical location, and so on) and detailed financial information (gross output of an industry, revenue, management fee, subsidized revenue, value of export delivery, and so on). In this study, nonmanufacturing enterprises in the database were removed in accordance with China's industrial classification for national economic activities. Then, the industrial classification around the year 2003 was arranged as a standardized tertiary industrial classification according to Brandt et al.'s [37] adjusted classification standards. Next, the administrative division codes of a sampled year in the data sample were adjusted in accordance with $\mathrm{Lu}$ and Tao's
[38] method. Lastly, the study by Brandt et al. [7] served as a reference for the omission of samples with missing information of industry gross output and annual average balance of net value of fixed assets, samples with a lower accumulated depreciation than the depreciation of the current year, samples with lower total assets than current assets, samples with lower total assets than the annual average balance of net value of fixed assets, and samples with less than eight employees.

4.2. Measurement Models. The degree of productivity dispersion among enterprises in an industry is an effective proxy variable for describing the industry's efficiency of resource allocation. According to market competition mechanisms, enterprises with lower productivity will exit the market. When a market is in equilibrium, the productivity of all enterprises should be similar and the degree of productivity dispersion should be zero [2]. If a market factor becomes distorted, enterprises with lower productivity will continue to occupy a share of resources and will be unable to exit the market in an orderly manner. Consequently, the degree of productivity dispersion among enterprises will no longer become zero. A higher degree of productivity dispersion indicates a lower efficiency of resource allocation. With these questions in mind, the effects of the administrative examination and approval system reform on the degree of productivity dispersion were utilized in this study to determine if the reform was able to promote improvements in an industry's efficiency of resource allocation. If the reform of the administrative examination and approval system was able to reduce the degree of productivity dispersion among enterprises in an industry, it can be concluded that the reform had also enhanced the industry's efficiency of resource allocation. Therefore, the methods developed by Bertrand et al. [39] served as a reference in this study with respect to the construction of the regression model for empirical analysis, as shown in the following equation: 


$$
\begin{aligned}
\text { dispersion }_{\mathrm{ict}}= & \alpha_{0}+\alpha_{1} \operatorname{AEASR}_{\mathrm{ct}}+\sum_{p=1}^{n} \beta_{p} C t r_{\text {pict }} \\
& +\mu_{i}+\gamma_{c}+\nu_{t}+\varepsilon_{\mathrm{ict}},
\end{aligned}
$$

where $t, c$, and $i$ are, respectively, the year, city, and threedigit standard industrial classification $(S I C)$ code. Dispersion is the dependent variable representing the degree of productivity dispersion among enterprises in an industry $i$ in a city $c$ for the year $t$. AEASR is the core independent variable representing the degree of administrative examination and approval system reform in each city. Ctr is a set of control variables which could affect the degree of productivity dispersion of an enterprise. In this study, an industry's fixed cost (FC), sunk cost (SC), export percentage (Export), subsidy percentage (SOE), foreign investment enterprises percentage (FIE), and market competitiveness (HHI) were added into the control variables in accordance with the studies by Balasubramanian and Sivadasan [25], Ding et al. [27], and Melitz [40]. $\mu, \gamma$, and $\nu$ are, respectively, the fixed effects of an industry, the fixed effects of a city, and the fixed effects of a year. $\varepsilon$ is a random error term.

\subsection{Measurement of Variables}

4.3.1. Efficiency of Resource Allocation. To measure the dispersion of productivity among firms in the industry, we first measured the productivity of the firm. Since we estimated the productivity of enterprises based on the 1998-2007 China Industrial Enterprise Database, estimating the productivity with the traditional ordinary least squares (OLS) method will bring about the missing variables and considering the problem of sample selection bias caused by the entry and exit of enterprises, so to overcome these problems, the paper calculated the firm productivity by using the method of Olley and Pakes [41]. The estimated model is shown in the following equation:

$$
Y_{f t}=\beta_{0}+\beta_{L} L_{f t}+\beta_{K} K_{f t}+\beta_{M} M_{f t}+\eta_{f t}+\varepsilon_{f t},
$$

in which $Y, L, K$, and $M$ represent, respectively, the enterprise output, number of employees, capital stock, and log of intermediate inputs; $\eta_{f t}$ are productivity shocks observable to the enterprise decision makers but not to the researchers; $\varepsilon_{f t}$ are the productivity shocks unobservable to the enterprise decision makers and the researchers. The conventional OLS approach neglects the existence of $\eta_{f t}$. However, as an enterprise's labor employment decisions and investments are influenced by productivity shocks $\eta_{f t}$, and the direct use of the conventional OLS method for calculation will result in endogeneity and biased regression results. According to the core concept of Olley and Pakes's [41] approach, if a positive correlation exists between enterprise investments and productivity, the productivity shocks $\eta_{f t}$ can be written as a function of enterprise investment. This function can be substituted to equation (2) to correct for the missing variables brought by the productivity shocks $\eta_{f t}$. Hence, the productivity level of each enterprise can be calculated on this basis $^{1}$
This study utilized standard deviations to measure the degree of productivity dispersion among the enterprises in an industry. A smaller standard deviation indicates a lower degree of productivity dispersion and a higher efficiency of resource allocation. The measurement model for the degree of productivity dispersion is expressed in the following equation:

$$
\text { dispersion }_{\mathrm{ict}}=\sqrt{\frac{1}{N} \sum_{f=1}^{N}\left(\ln t f p_{f i c t}-\overline{\ln t f p_{\mathrm{ict}}}\right)^{2}} .
$$

in which $N$ corresponds to the number of enterprises in an industry; In $t f p_{\text {fict }}$ represents the log productivity of an enterprise $f$ in an industry $i$ in a city $c$ for the year $t$; and $\overline{\ln t f p_{\text {ict }}}$ represents the average of the log productivity levels of all enterprises in an industry $i$ in a city $c$ for the year $t$.

\subsubsection{Administrative Examination and Approval System} Reform. The administrative examination and approval center is the centerpiece for China's administrative examination and approval system reform. It allows for a simplified and centralized approach to the handling of administrative examination and approval items and reduces the institutional transaction cost of an enterprise. As it has collection, integration, and innovation functions, it is a key determinant for the comprehensive deepening of the reform. Therefore, the progress of the reform can be reflected by the establishment of administrative examination and approval centers. Based on the methodology developed by Zhu and Zhang [42], this study set the establishment of an administrative examination and approval center as a dummy variable to depict the progress of the reform in a city. If a city $c$ establishes an administrative examination and approval center in the year $t$, the valuation of AEASR becomes 1 during year $t$ and after the years after it, while the valuation of other years become 0 .

\subsubsection{Control Variables}

(1) Fixed Cost. It is defined as the ratio between the management fee and the added value of an enterprise in an industry. In an industry with a higher fixed cost, a higher productivity level must be attained by an enterprise to become profitable. In other words, a fixed cost will enhance the critical productivity level of an industry, thus allowing enterprises with low productivity levels to exit the market and reducing the degree of enterprise productivity dispersion [25].

(2) Sunk Cost. It is defined as the ratio between the capital stock and the added value of an industry. When facing emerging enterprises, existing enterprises often employ strategic actions to increase the sunk cost of entering an industry, thus blocking the market entry of new enterprises and enhancing the market power of enterprises in an industry. Consequently, the critical productivity level of an industry is lowered, and existing low productivity 
enterprises are still able to benefit from high prices and maintain their presence in the industry, which increases the degree of productivity dispersion among enterprises $[43,44]$.

(3) Export Percentage. It is defined as the ratio between the total export volume and the sales volume of an enterprise in an industry. The theory of heterogeneous firms and trade proposed by Melitz [40] stresses the decisive role of productivity in an enterprise's export operations. An export market is able to self-select high productivity enterprises to participate in the export market. According to the theory, exports are beneficial for markets to realize optimal configurations. Therefore, low productivity enterprises will exit the market while high productivity enterprises will account for a higher share, thereby reducing the degree of productivity dispersion.

(4) Subsidy Percentage. It is defined as the ratio between the total government subsidies and the sales volume of an enterprise in an industry. China's subsidy policies have a tendency to "protect the weak." Hence, low productivity enterprises are better able to obtain government subsidies and occupy production resources for a long period. In addition, as they are unable to exit the market, the degree of productivity dispersion of an industry is increased.

(5) Foreign Investment Enterprises Percentage. It is defined as the ratio between the number of foreign investment enterprises and the total number of enterprises in an industry. The extent of the influence of foreign investment enterprises on the degree of productivity dispersion of enterprises in an industry remains unclear. On the other hand, foreign investment enterprises have higher productivity levels [45]. When a foreign investment enterprise enters a host country and starts to operate, a large productivity gap is generated between the enterprise and the host country's enterprises, thereby extending the degree of productivity dispersion among enterprises. In addition, a foreign investment enterprise will create competition when it enters a local market. Under the pressure of competition from a foreign investment enterprise, low productivity enterprises will exit the market of the host country, thereby reducing the degree of productivity dispersion among the enterprises in an industry.

(6) Market Competitiveness. The Herfindahl-Hirschman Index was used in this study to estimate market competition. The equation is expressed as $\mathrm{HHI}_{\mathrm{ict}}=\sum_{f \in I_{i}}\left(\right.$ Sale $_{\text {fict }} /$ Sale $\left._{\text {ict }}\right)^{2}$, in which Sale fict $_{\text {and Sale }}$ ict are, respectively, the sales volume of an enterprise $f$ in an industry $i$ in a city $c$ for the year $t$ and the sales volume of an industry $i$ in a city $c$ for the year $t$. The index ranges from 0 to 1 , and a larger value indicates lower market competitiveness. An increase in market competitiveness will promote high productivity enterprises to enter the market and low productivity enterprises will exit the market, thereby reducing the degree of productivity dispersion among the enterprises in an industry.

\section{Empirical Results and Analysis}

5.1. Basic Regression Results. Based on the regression model in equation (1), the OLS approach was used in this study for the empirical validation of the impacts of the administrative examination and approval system reform on the degree of productivity dispersion. The basic regression results are shown in Table 1.

Table 1 reports the relevant estimation results obtained through the gradual addition of control variables. In Row (1), no control variables are added, and the fixed effects of an industry, city, and year are uncontrolled. The estimated coefficient of the variable AEASR is -0.1074 , which is statistically significant at a $1 \%$ level. This suggests that the degree of productivity dispersion among enterprises is lower in cities with an administrative examination and approval center. In Row (2), the fixed effects of an industry, city, and year are controlled. The estimated coefficient of AEASR is -0.0186 , which is statistically significant at a $1 \%$ level. It can be seen that the inhibitory effects of the administrative examination and approval system reform on the degree of productivity dispersion are comparatively lower than the estimation results in Row (1). Therefore, the omission of dependent variables will overestimate the policy effects of the administrative examination and approval system reform. Based on the results of Row (2), the control variables of fixed cost, sunk cost, export percentage, subsidy percentage, foreign investment enterprises percentage, and market competitiveness are added into Row (3). After controlling for these variables, the estimated coefficient of AEASR remains negative and statistically significant, and the value is similar to that in Row (2). The estimation results in Table 1 suggest that the establishment of administrative examination and approval centers was beneficial for reducing the degree of industry productivity dispersion, thereby delineating the improvement effects of the reform on the efficiency of resource allocation.

Next, the control variables in Table 1 are described in brief as follows. The estimated coefficients of fixed cost (FC) and export percentage (Export) are negative and statistically significant. This shows that the degree of productivity dispersion among enterprises is lower in an industry with a higher fixed cost and export percentage. On the other hand, the estimated coefficients of sunk cost (SC) and subsidy percentage (Subsidy) are positive and statistically significant. This shows that an industry with a higher sunk cost will receive more government subsidies, which increases the degree of productivity dispersion. However, the estimated coefficient of foreign investment enterprises (FIE) percentage had failed to pass the test of significance. As described in the measurement of variables section, the foreign investment enterprises percentage has negative and positive effects on the degree of productivity dispersion. Hence, as a whole, this variable is unable to generate significant effects with regard to the degree of productivity dispersion. The estimated coefficient of market competitiveness (HHI) is positive and statistically significant at a $1 \%$ level. This suggests that the degree of productivity dispersion is greater in an industry with lower market competitiveness. 
TABLE 1: Basic regression results.

\begin{tabular}{lccc}
\hline Variables & $(1)$ & $(2)$ & $(3)$ \\
\hline \multirow{2}{*}{ AEASR } & $-0.1074^{* * *}$ & $-0.0186^{* * *}$ & $-0.0188^{* * *}$ \\
& $(0.0029)$ & $(0.0053)$ & $(0.0053)$ \\
FC & & & $-0.0008^{* *}$ \\
& & & $(0.0004)$ \\
SC & & & $0.0002^{*}$ \\
& & & $(0.0001)$ \\
Export & & & $-0.0206^{* *}$ \\
& & & $(0.0088)$ \\
Subsidy & & & $0.2072^{* *}$ \\
& & & $(0.0985)$ \\
FIE & & & -0.0067 \\
& & & $(0.0091)$ \\
HHI & & & $0.1465^{* * *}$ \\
Industry fixed effect & $\mathrm{N}$ & $\mathrm{Y}$ & $(0.0084)$ \\
City fixed effect & $\mathrm{N}$ & $\mathrm{Y}$ & $\mathrm{Y}$ \\
Year fixed effect & $\mathrm{N}$ & $\mathrm{Y}$ & $\mathrm{Y}$ \\
$R^{2}$ & 0.0091 & 0.0935 & 0.0967 \\
Sample size & 148498 & 148498 & 148302 \\
\hline
\end{tabular}

Note. Symbols ${ }^{*},{ }^{* *}$, and ${ }^{* * *}$ represented significance levels of $10 \%, 5 \%$, and $1 \%$, respectively; the numbers in brackets were robust standard errors of estimated coefficients.

Therefore, market competitiveness promotes the improvement of an industry's efficiency of resource allocation.

\subsection{Robustness Tests}

5.2.1. Treatment of Endogeneity. The estimation results in this study could be affected by endogeneity. To address this issue, the researchers first omitted samples with suspected endogeneity and then selected instrumental variables of the administrative examination and approval system reform. Next, the effects of the reform on the degree of productivity dispersion were re-estimated through a two-step OLS approach.

In 2001, China began its nationwide plan to reform the administrative examination and approval system. Under the context of a nationwide unified plan, many cities began to establish administrative examination and approval centers. For samples involving these cities, the establishment of administrative examination and approval centers can be regarded as exogenous. However, some cities had voluntarily implemented the reform by establishing an administrative examination and approval center even before the nationwide plan, possibly as to stimulate market vitality and eliminate excess capacity. Therefore, samples involving cities with an administrative examination and approval center established before 2001 are suspected to be endogenous. To avoid the impacts of endogeneity on the estimation results, samples involving cities with an administrative examination and approval center established before 2001 were omitted. The estimation results are shown in Row (1) in Table 2. The estimated coefficients of the variable AEASR are all negative, which suggests that the degree of productivity dispersion among enterprises is lower in cities with an administrative examination and approval center. As a result, an industry's efficiency of resource allocation can be improved effectively.
Next, instrumental variable regression was performed as a further treatment of endogeneity. The instrumental variable was set as the rate of administrative examination and approval center establishment in other cities within the same province. This instrumental variable was chosen as the innovation of China's local governments is proliferative [42]. If the administrative examination and approval system reform had taken place in a certain city, other cities will be prompted to implement the reform as well. Furthermore, the degree of productivity dispersion among the enterprises in an industry in a city has no direct effects on the rate of administrative examination and approval center establishment in other cities. Therefore, a two-step OLS estimation was performed in this study with the aforementioned instrumental variable so as to re-examine whether the administrative examination and approval system reform had improved the efficiency of resource allocation. The regression results are shown in Row (2) in Table 2. The estimated coefficient of AEASR is negative and statistically significant, which suggests that the reform had improved the efficiency of resource allocation Furthermore, the results of the test of under identification and the test of weak identification have passed the test of significance at a $1 \%$ level. Hence, the selected instrumental variable is appropriate, and the twostep OLS approach for regression analysis is effective.

5.2.2. Regression Analysis for Different Industries. In order to understand the impacts of the administrative examination and approval system reform on the efficiency of resource allocation, the basic regression in this study was performed according to the three-digit SIC codes. The three-digit SIC codes were chosen based on two considerations. If the twodigit SIC codes were to be used to calculate the degree of productivity dispersion among enterprises, the scope of industry classification may be overly large and the heterogeneity of industries would be unaccounted for. If the fourdigit SIC does were to be used to calculate the degree of productivity dispersion, the number of enterprises in an industry may be too small, which affects the effectiveness of the degree of dispersion measurement. However, in order to support the robustness of the conclusions of this study, the researchers also examined the impacts of the administrative examination and approval system reform on the efficiency of resource allocation by using the two-digit and four-digit SIC codes. Table 2 shows the corresponding estimation results. The estimation results using the two-digit SIC codes are listed in Row (3); the estimation results using the four-digit SIC codes are listed in Row (4). The regression results indicate that regardless of two-digit or four-digit SIC codes, the estimated coefficients of AEASR are both negative and statistically significant. Hence, the conclusion that the administrative examination and approval system reform had enhanced the efficiency of resource allocation is robust.

\subsubsection{Remeasurement of Efficiency of Resource Allocation.} The measurement index of the efficiency of resource allocation is affected by two factors: one is the method for measuring productivity dispersion and the other is the 
TABLE 2: Robustness test results.

\begin{tabular}{|c|c|c|c|c|c|c|c|c|}
\hline & (1) & $(2)$ & (3) & $(4)$ & $(5)$ & $(6)$ & $(7)$ & $(8)$ \\
\hline AEASR & $\begin{array}{c}-0.0199^{* * *} \\
(0.0057)\end{array}$ & $\begin{array}{c}-0.0435^{* *} \\
(0.0206)\end{array}$ & $\begin{array}{c}-0.0164^{* *} \\
(0.0071)\end{array}$ & $\begin{array}{c}-0.0152^{* * *} \\
(0.0049)\end{array}$ & $\begin{array}{c}-0.0148^{* *} \\
(0.0066)\end{array}$ & $\begin{array}{c}-0.0219^{* * *} \\
(0.0084)\end{array}$ & $\begin{array}{c}-0.0123^{* *} \\
(0.0053)\end{array}$ & $\begin{array}{l}-0.0032 \\
(0.0062)\end{array}$ \\
\hline FC & $\begin{array}{c}-0.0008^{* *} \\
(0.0003)\end{array}$ & $\begin{array}{c}-0.0008^{* *} \\
(0.0004)\end{array}$ & $\begin{array}{c}-0.0051^{* *} \\
(0.0021)\end{array}$ & $\begin{array}{l}-0.0002 \\
(0.0008)\end{array}$ & $\begin{array}{l}-0.0000 \\
(0.0001)\end{array}$ & $\begin{array}{l}-0.0000 \\
(0.0001)\end{array}$ & $\begin{array}{l}-0.0002 \\
(0.0002)\end{array}$ & $\begin{array}{c}-0.0008^{* *} \\
(0.0004)\end{array}$ \\
\hline SC & $\begin{array}{l}0.0002^{*} \\
(0.0001)\end{array}$ & $\begin{array}{l}0.0002^{*} \\
(0.0001)\end{array}$ & $\begin{array}{c}0.0006^{* * *} \\
(0.0002)\end{array}$ & $\begin{array}{c}0.0002 \\
(0.0001)\end{array}$ & $\begin{array}{c}-0.0000^{*} \\
(0.0000)\end{array}$ & $\begin{array}{l}-0.0000 \\
(0.0000)\end{array}$ & $\begin{array}{c}0.0001 \\
(0.0000)\end{array}$ & $\begin{array}{l}0.0002^{*} \\
(0.0001)\end{array}$ \\
\hline Export & $\begin{array}{l}-0.0136 \\
(0.0095)\end{array}$ & $\begin{array}{c}-0.0203^{* *} \\
(0.0088)\end{array}$ & $\begin{array}{c}-0.0575^{* * *} \\
(0.0153)\end{array}$ & $\begin{array}{r}-0.0141^{*} \\
(0.0074)\end{array}$ & $\begin{array}{c}0.0058 \\
(0.0094)\end{array}$ & $\begin{array}{c}0.0748^{* * *} \\
(0.0115)\end{array}$ & $\begin{array}{c}0.0732^{* * * *} \\
(0.0087)\end{array}$ & $\begin{array}{c}-0.0206^{* *} \\
(0.0088)\end{array}$ \\
\hline Subsidy & $\begin{array}{l}0.2108^{* *} \\
(0.1020)\end{array}$ & $\begin{array}{l}0.2191^{* *} \\
(0.1005)\end{array}$ & $\begin{array}{l}0.2566^{*} \\
(0.1352)\end{array}$ & $\begin{array}{c}0.2335^{* * *} \\
(0.0682)\end{array}$ & $\begin{array}{c}-0.0273^{*} \\
(0.0140)\end{array}$ & $\begin{array}{l}-0.0322 \\
(0.0198)\end{array}$ & $\begin{array}{l}-0.0292 \\
(0.1041)\end{array}$ & $\begin{array}{c}0.2072^{* *} \\
(0.0986)\end{array}$ \\
\hline FIE & $\begin{array}{l}-0.0054 \\
(0.0097)\end{array}$ & $\begin{array}{r}-0.0065 \\
(0.0091)\end{array}$ & $\begin{array}{l}-0.0032 \\
(0.0177)\end{array}$ & $\begin{array}{l}-0.0067 \\
(0.0073)\end{array}$ & $\begin{array}{c}0.0340^{* * * *} \\
(0.0078)\end{array}$ & $\begin{array}{c}0.0295^{* * * *} \\
(0.0091)\end{array}$ & $\begin{array}{c}0.0075 \\
(0.0092)\end{array}$ & $\begin{array}{l}-0.0070 \\
(0.0091)\end{array}$ \\
\hline HHI & $\begin{array}{c}0.1545^{* * *} \\
(0.0089)\end{array}$ & $\begin{array}{c}0.1464^{* * *} \\
(0.0084)\end{array}$ & $\begin{array}{c}0.0902^{* * * *} \\
(0.0134)\end{array}$ & $\begin{array}{c}0.1878^{* * *} \\
(0.0074)\end{array}$ & $\begin{array}{c}-1.2383^{* * *} \\
(0.0061)\end{array}$ & $\begin{array}{c}-2.4056^{* * *} \\
(0.0079)\end{array}$ & $\begin{array}{c}0.6683^{* * *} \\
(0.0085)\end{array}$ & $\begin{array}{c}0.1465^{* * *} \\
(0.0084)\end{array}$ \\
\hline Industry fixed effect & $\mathrm{Y}$ & $\mathrm{Y}$ & $\mathrm{Y}$ & $\mathrm{Y}$ & $\mathrm{Y}$ & $\mathrm{Y}$ & $\mathrm{Y}$ & $\mathrm{Y}$ \\
\hline City fixed effect & $\mathrm{Y}$ & $\mathrm{Y}$ & $\mathrm{Y}$ & $\mathrm{Y}$ & $\mathrm{Y}$ & $\mathrm{Y}$ & Y & $\mathrm{Y}$ \\
\hline Year fixed effect & $\mathrm{Y}$ & $\mathrm{Y}$ & $\mathrm{Y}$ & $\mathrm{Y}$ & $\mathrm{Y}$ & $\mathrm{Y}$ & $\mathrm{Y}$ & $\mathrm{Y}$ \\
\hline Under identification test & & $7837.9620^{* * *}$ & & & & & & \\
\hline $\begin{array}{l}\text { Weak identification test } \\
R^{2}\end{array}$ & 0.0965 & $\begin{array}{c}9258.8740^{* * *} \\
0.0966\end{array}$ & 0.1385 & .0 & 77 & 0.4333 & 0.1 & 0.0966 \\
\hline Sample size & 133509 & 148082 & 60237 & 190427 & 218971 & 218971 & 148302 & 148302 \\
\hline
\end{tabular}

Note. Symbols * , **, and ${ }^{* * *}$ represent, respectively, the $10 \%, 5 \%$, and $1 \%$ level of significance; the numbers in brackets are robust standard deviations; the under identification test refers to the Kleibergen-Paap rk LM statistic in the test, the null hypothesis is that an under identification problem exists in the instrumental variable regression; the weak identification test refers to the Kleibergen-Paap rk Wald F statistic in the test; the null hypothesis is that a weak identification problem exists in the instrumental variable regression.

method for calculating enterprise productivity level. Both factors will result in differences in the measurement of the efficiency of resource allocation. Therefore, the efficiency of resource allocation was remeasured in this stud so as to ensure the robustness of the conclusions.

First, the method for measuring the degree of productivity dispersion was changed. The basic regression results utilized standard deviations to measure the degree of productivity dispersion among enterprises as well as the efficiency of resource allocation of an industry. There are many methods for measuring the degree of productivity dispersion, such as quartile deviation and 90/10 percentile deviation. Therefore, in order to validate that the regression results were unaffected by the methods for measuring the degree of productivity dispersion, quartile deviation and 90/ 10 percentile deviation were used to remeasure the degree of productivity dispersion among the enterprises in an industry. In quartile deviation, the 25th percentile of productivity was subtracted from the 75 th percentile; in $90 / 10$ percentile deviation, the 10th percentile of productivity was subtracted from the 90th percentile. A larger deviation in both approaches indicates a higher degree of productivity dispersion and a lower efficiency of resource allocation. The regression results of the quartile deviation are listed in Row (5) in Table 2; the regression results of the 90/10 percentile deviation are listed in Row (6). The results indicate that regardless of indexes for measuring the degree of productivity dispersion, the estimated coefficients of AEASR are both negative and statistically significant. Hence, the establishment of administrative examination and approval centers in a city is beneficial for reducing the city's degree of productivity dispersion among the enterprises in an industry, thereby improving the efficiency of resource allocation.

Next, the method for measuring enterprise productivity level was changed. This study re-estimated an enterprise's productivity level in accordance with the methodology of Levinsohn and Petrin [46]. Standard deviations were also used to measure the degree of productivity dispersion among enterprises. Row (7) in Table 2 reports the estimation results re-measured according to Levinsohn and Petrin's methodology. The results indicate that the estimated coefficients of AEASR are all negative and statistically significant. Hence, the conclusion that the administrative examination and approval system reform had enhanced the efficiency of resource allocation is unaffected by the measurement methods.

5.2.4. Remeasurement of the Reform of Administrative Examination and Approval. The basic regression model uses whether the administrative examination and approval center is established to measure the reform, which takes the reform of administrative examination and approval degree of the city with the administrative examination and approval center as the same, but in fact, the degree of the administrative examination and approval reform differs in different cities. Therefore, this section will use other indicators to 
remeasure the reform of administrative examination and approval and then test the robustness of the research conclusion. The reform of administrative examination and approval will be analyzed from two aspects.

First of all, generally speaking, the higher the degree of administrative examination and approval reform is, the higher the degree of marketization will be, and the more the market can play its role in resource allocation so as to realize the effective allocation of resources. Therefore, this paper constructs an interactive item (AEASR-MARKET) between administrative examination and approval center and marketization degree to measure the degree of administrative examination and approval reform in each city. The marketization degree index includes five aspects: the relationship between government and market, the development of nonstate-owned economy, the development of product market, the development of factor market, and the development of market intermediary organizations and the legal system environment The composition of the index comes from "China's marketization index Report on the relative process of marketization in various regions in 2009." As shown in column (1) of Table 3, the estimated coefficient of AEASR-MARKET is -0.0021 , which is significant at the significance level of $1 \%$. It shows that the higher the degree of urban administrative examination and approval reform, the more helpful it is to reduce the degree of productivity dispersion among enterprises in the city, thereby improving the efficiency of resource allocation in the industry.

Secondly, this paper uses China's "Business Environment Report" released by the World Bank in 2008 to measure the degree of administrative examination and approval. The report investigates the administrative examination and approval procedures and time required to set up enterprises in four municipalities directly under the central government and 27 provincial capital cities in 2006. Based on these two indicators and cross-sectional data of 31 cities in 2006, this paper explores the impact of the reform of administrative examination and approval on resource allocation efficiency. The regression results in columns (2) and (3) of Table 3 show that the estimated coefficients of the administrative examination and approval procedure (Procedure) and administrative examination and approval time (Day) are both positive at the $1 \%$ significance level. This shows that in cities with stricter administrative examination and approval, the higher the dispersion degree of productivity among enterprises in the industry, the lower the efficiency of resource allocation. That is to say, cities with less administrative examination and approval procedures and time can improve the efficiency of resource allocation.

5.2.5. Placebo Test. A placebo test is a counterfactual test in which counterfactual hypotheses are proposed to determine the impacts of a policy or an event. In the placebo test of this study, the time of establishment of the administrative examination and approval center in each city was changed. If a spurious regression exists within the basic regression, changing the time of center establishment would indicate the conclusion that the reform had improved the efficiency of resource allocation and is still significant. Hence, the time of center establishment was brought forward for three years so as to understand the impacts of the administrative examination and approval system reform on the degree of productivity dispersion. As shown in Row (8) in Table 2, AEASR has no longer significant. Therefore, if the time of center establishment was manually changed, the impacts of the administrative examination and approval system reform on the degree of productivity dispersion would no longer be significant. In other terms, based on the placebo test results, it can be highlighted that the reform had reduced the degree of productivity dispersion among the enterprises in an industry, as well as enhancing the industry's efficiency of resource allocation.

\section{Tests of Heterogeneity}

This study assumes that market entry and exit play an important role throughout the process of the reform's influence on the efficiency of resource allocation. Hence, a further test was performed to investigate the heterogeneity of the effects of the reform on the efficiency of resource allocation at different market entry and exit rates.

6.1. Influence of Administrative Examination and Approval Reform on Resource Allocation Efficiency in Different Samples. In general, new enterprises have higher productivity levels, and the production resources often flow from low productivity enterprises to high productivity enterprises, thereby achieving effective resource allocation. Following the continuous entry of new enterprises, market competitiveness is constantly intensified, which promotes low productivity enterprises to exit the market. Once these enterprises exit the market, they will release resources for use by high productivity enterprises, thereby optimizing the efficiency of resource allocation. If the administrative examination and approval system reform was able to improve the efficiency of resource allocation through the promotion of market entry and exit, then the positive effects of the reform on the efficiency of resource allocation would be more significant for industries with lower entry and exit rates. In order to determine the heterogeneity of this effect, a split sample regression was performed in this study according to the entry rates and exit rates of different industries, thereby examining the effects of the reform on the efficiency of resource allocation in different samples.

The entry and exit status of an enterprise is first examined to estimate an industry's entry rate and exit rate. For instance, if an enterprise exists in year $t$ but not in year $t-1$, it can be assumed that the enterprise had entered the market in year $t$; if an enterprise exists in year $t$ but no longer exists in year $t+1$, it can be assumed that the enterprise had exited the market in year $t$. Since this study uses data from the China Industry Business Performance Database from 1998 to 2007 , the researchers are unable to determine if enterprises in 1998 existed in the year before nor if enterprises in 2007 existed in the year after. Hence, samples in 1998 were not considered when examining the market entry of 
TABLE 3: Remeasurement results of the reform of administrative examination and approval.

\begin{tabular}{|c|c|c|c|}
\hline & $(1)$ & $(2)$ & (3) \\
\hline AEASR-MARKET & $\begin{array}{l}-0.0021 * \\
-0.0005\end{array}$ & & \\
\hline Procedure & & $\begin{array}{c}0.0730^{* * * *} \\
(0.0110)\end{array}$ & \\
\hline Day & & & $\begin{array}{c}0.0077^{* * *} \\
(0.0018)\end{array}$ \\
\hline FC & $\begin{array}{c}-0.0008^{* *} \\
-0.0004\end{array}$ & $\begin{array}{l}-0.0259 \\
(0.0370)\end{array}$ & $\begin{array}{l}-0.0205 \\
(0.0370)\end{array}$ \\
\hline SC & $\begin{array}{l}0.0002 * \\
-0.0001\end{array}$ & $\begin{array}{c}0.0025 \\
(0.0031)\end{array}$ & $\begin{array}{c}0.0020 \\
(0.0031)\end{array}$ \\
\hline Export & $\begin{array}{l}-0.0444^{* * *} \\
-0.0086\end{array}$ & $\begin{array}{c}0.0237 \\
(0.0664)\end{array}$ & $\begin{array}{c}0.0112 \\
(0.0668)\end{array}$ \\
\hline Subsidy & $\begin{array}{l}0.2215^{* *} \\
-0.0984\end{array}$ & $\begin{array}{c}-2.0272^{* *} \\
(0.8972)\end{array}$ & $\begin{array}{c}-2.1744^{* *} \\
(0.9043)\end{array}$ \\
\hline FIE & $\begin{array}{l}0.0588^{* * *} \\
-0.0083\end{array}$ & $\begin{array}{l}0.1004^{*} \\
(0.0594)\end{array}$ & $\begin{array}{l}0.1137^{*} \\
(0.0608)\end{array}$ \\
\hline HHI & $\begin{array}{c}0.0887^{* * *} \\
-0.0081\end{array}$ & $\begin{array}{l}-0.0385 \\
(0.0597)\end{array}$ & $\begin{array}{l}-0.0776 \\
(0.0603)\end{array}$ \\
\hline Industry fixed effect & Control & Control & Control \\
\hline City fixed effect & Control & No & No \\
\hline Year fixed effect & Control & No & No \\
\hline $\begin{array}{l}\text { Pseudo goodness of fit } \\
\text { Sample size }\end{array}$ & $\begin{array}{c}0.07 \\
148300\end{array}$ & $\begin{array}{l}0.136 \\
2911\end{array}$ & $\begin{array}{l}0.132 \\
2911\end{array}$ \\
\hline
\end{tabular}

Note. Symbols ${ }^{*},{ }^{* *}$, and ${ }^{* * *}$ represent $10 \%, 5 \%$, and $1 \%$ significance levels respectively; the values in brackets are robust standard deviation.

enterprises nor were samples in 2007 when examining the market exit of enterprises. After examining the entry status and exit status of enterprises, this study defined industry entry rate as the percentage of the quantity of new enterprises entering the market to the total number of enterprises, while industry exit rate was defined as the percentage of the quantity of enterprises exiting the market to the total number of enterprises. In this study, an industry with a higher than average entry rate is categorized as an industry with a high entry rate, whereas an industry with a lower than average entry rate is categorized as an industry with a low entry rate. Industries with high and low exit rates are categorized in a similar fashion.

Table 4 shows the split sample regression results. Rows (1) and (2) are the estimation results of industries with different entry rates. For industries with high entry rates, the estimated coefficient of the reform is -0.0143 , which is statistically significant at a $10 \%$ level; for industries with low entry rates, the estimated coefficient of the reform is -0.0278 , which is statistically significant at a $1 \%$ level. Therefore, it can be seen that the reform was able to promote more industries with low entry rates to enter the market, thereby reducing the degree of productivity dispersion among enterprises and increasing the efficiency of resource allocation. As enterprises in industries with high entry rates are more proactive in market entry, the effects of the reform are less prominent. Rows (3) and (4) are the estimation results of industries with different exit rates. For industries with high exit rates, the estimated coefficient of the reform is -0.0153 , which is statistically significant at a $5 \%$ level; for industries with low exit rates, the estimated coefficient of the reform is -0.0287 , which is statistically significant at a $1 \%$ level. In comparison, the positive effects of the reform on the efficiency of resource allocation are more prominent in industries with low exit rates. This is due to the high market exit tendency of enterprises in industries with high exit rates. These enterprises will exit the market even without the reform. Thus, the positive effects of the reform on the efficiency of resource allocation are less prominent in industries with high exit rates. In contrast, the reform promotes the entry of industries with lower exit rates, which stimulates market vitality and enhances the exit tendency of enterprises in these industries. This greatly reduces the degree of productivity dispersion among the enterprises in the industries.

\subsection{Inhibitory Effect of Administrative Approval Reform on} Zombie Companies. China's administrative examination and approval reform has significantly inhibited the formation of zombie companies, smoothed market entry mechanisms, and improved the efficiency of resource allocation. On the one hand, the reform of administrative examination and approval means the streamlining of examination and approval procedures, the decentralization of examination and approval matters, and the integration of examination and approval services, which can reduce rent-seeking activities caused by administrative examination and approval, reduce institutional transaction costs, stimulate productive entrepreneurship, and improve enterprises innovation level. On the other hand, incumbent companies that are about to go bankrupt usually have large assets and a large number of employees. If these companies go bankrupt, it will affect the local economy and employment to a certain extent. Therefore, the local government will help these enterprises so that they will not die. The reform of administrative examination and approval reduces entry costs and barriers and promotes market entry to achieve "dual growth" of economy and employment. With the increase in market vitality, the adverse effects of enterprises' withdrawal from the market will be weakened, which will reduce the motivation of government to rescue enterprises that should have withdrawn from the market, inhibit the formation of zombie companies, and improve the efficiency of resource allocation. In order to test this impact mechanism, this article first identifies zombie companies, then calculates the proportion of zombie companies in the industry, and uses this proportion to measure zombie companies. Finally, on this basis, we empirically test the inhibitory effect of administrative approval reform on the formation of zombie companies.

For the identification method of zombie companies, this article is based on the scholars such as Caballero et al. [33] and Fukuda and Nakamura [35] to identify and analyze the zombie companies in the Chinese industrial enterprise database. The specific identification methods are as follows:

(1) Calculate the interest rate difference of the enterprise in period $t$. The interest rate difference is defined as the difference between the actual interest paid by the 
TABLE 4: Heterogeneity test results.

\begin{tabular}{|c|c|c|c|c|}
\hline & $\begin{array}{c}(1) \\
\text { High entry rate }\end{array}$ & $\begin{array}{c}(2) \\
\text { Low entry rate }\end{array}$ & $\begin{array}{c}\text { (3) } \\
\text { High exit rate }\end{array}$ & $\begin{array}{c}(4) \\
\text { Low exit rate }\end{array}$ \\
\hline AEASR & $\begin{array}{c}-0.0143 * \\
(0.0076)\end{array}$ & $\begin{array}{c}-0.0278^{* * *} \\
(0.0076)\end{array}$ & $\begin{array}{c}-0.0153 * * \\
(0.0072)\end{array}$ & $\begin{array}{c}-0.0287^{* * *} \\
(0.0080)\end{array}$ \\
\hline $\mathrm{FC}$ & $\begin{array}{l}-0.0026 \\
(0.0017)\end{array}$ & $\begin{array}{c}-0.0026^{* *} \\
(0.0012)\end{array}$ & $\begin{array}{l}-0.0025 \\
(0.0017)\end{array}$ & $\begin{array}{c}-0.0025^{* *} \\
(0.0012)\end{array}$ \\
\hline SC & $\begin{array}{l}0.0002^{*} \\
(0.0001)\end{array}$ & $\begin{array}{c}0.0007^{* *} \\
(0.0004)\end{array}$ & $\begin{array}{l}0.0002^{*} \\
(0.0001)\end{array}$ & $\begin{array}{c}0.0007^{* *} \\
(0.0004)\end{array}$ \\
\hline Export & $\begin{array}{c}-0.0359^{* * *} \\
(0.0121)\end{array}$ & $\begin{array}{l}-0.0019 \\
(0.0127)\end{array}$ & $\begin{array}{c}-0.0341^{* * *} \\
(0.0115)\end{array}$ & $\begin{array}{l}-0.0025 \\
(0.0134)\end{array}$ \\
\hline Subsidy & $\begin{array}{c}0.3271 * * * \\
(0.1044)\end{array}$ & $\begin{array}{c}0.0981 \\
(0.1567)\end{array}$ & $\begin{array}{c}0.3016^{* * *} \\
(0.1023)\end{array}$ & $\begin{array}{c}0.1258 \\
(0.1622)\end{array}$ \\
\hline FIE & $\begin{array}{c}0.0209 \\
(0.0133)\end{array}$ & $\begin{array}{c}-0.0267^{* *} \\
(0.0125)\end{array}$ & $\begin{array}{c}0.0186 \\
(0.0127)\end{array}$ & $\begin{array}{c}-0.0253^{*} \\
(0.0130)\end{array}$ \\
\hline $\mathrm{HHI}$ & $\begin{array}{c}0.1396^{* * *} * \\
(0.0120)\end{array}$ & $\begin{array}{c}0.1619^{* * *} \\
(0.0118)\end{array}$ & $\begin{array}{c}0.1366^{* * *} * \\
(0.0115)\end{array}$ & $\begin{array}{c}0.1784^{* * * *} \\
(0.0124)\end{array}$ \\
\hline Industry fixed effect & $\mathrm{Y}$ & $\mathrm{Y}$ & $\mathrm{Y}$ & $\mathrm{Y}$ \\
\hline City fixed effect & $\mathrm{Y}$ & $\mathrm{Y}$ & $\mathrm{Y}$ & $\mathrm{Y}$ \\
\hline Year fixed effect & $\mathrm{Y}$ & $\mathrm{Y}$ & $\mathrm{Y}$ & $\mathrm{Y}$ \\
\hline$R^{2}$ & 0.0996 & 0.1037 & 0.0979 & 0.1010 \\
\hline Sample size & 72865 & 75437 & 78854 & 69448 \\
\hline
\end{tabular}

Note. Symbols ${ }^{*},{ }^{* *}$, and ${ }^{* * *}$ represented significance levels of $10 \%, 5 \%$, and $1 \%$, respectively; the numbers in brackets were robust standard errors of estimated coefficients.

enterprise and the minimum interest payable and is standardized. The calculation formula is as follows:

$$
R_{f t}^{*}=r s_{t-1} \times B S_{f t-1}+\left(\frac{1}{5} \sum_{j=1}^{5} r l_{t-j}\right) \times B L_{f t-1}
$$

$\operatorname{EIR}_{f t}=\frac{R_{f t}-R_{f t}^{*}}{R_{f t}^{*}}$,

where EIR represents the interest rate difference; $R^{*}$ represents the minimum interest payable; $R$ represents the actual interest payment; $r s_{t-1}$ represents the lowest interest rate for short-term borrowing in $t$ - 1 ; $r l_{t-j}$ represents the lowest interest rate for long-term borrowing in $t-j$; and $B S_{f t-1}$ and $B L_{f t-1}$ are the shortterm loan balance and long-term loan balance of enterprise $f$ in $t-1$ year. In the database of Chinese industrial enterprises, the balance of short-term loans is represented by current liabilities, and the balance of long-term loans is represented by long-term liabilities.

(2) Calculate the company's income before interest and tax after deducting subsidy income in period $t$.

(3) Calculate the company's debt-to-asset ratio in period $t-1$ and the growth rate of its debt in period $t$.

According to the above calculations, if a company meets the following four conditions at the same time, it is considered as a zombie company. (1) The interest rate differential of the company in period $t$ is negative; (2) The company's income before interest and tax after deduction of subsidies in period $t$ is less than the minimum interest payable; (3) The debt to asset ratio of companies in $T-1$ period is higher than $50 \%$, and the debt growth rate in $t$ period is greater than 0 ; (4) The company was identified as a zombie company in both period $t-1$ and $t$. The first condition identifies companies that actually pay interest less than the minimum interest payable as zombie companies, indicating that companies that should have withdrawn from the market continue to exist in the market because of credit concessions and become zombie companies. The first condition is easy to identify companies with better qualifications and lower default risk that have obtained bank credit concessions as zombie companies or omit zombie companies that achieve "borrowing new loans to repay old debts" through loan extensions due to maturity. Therefore, adding the second condition and the third condition to solve the problem of identifying zombie companies in the first condition. The zombie companies identified based on the first three conditions are "one-off zombie companies." This may identify normal companies that only encountered short-term problems in their operation and management or suffered short-term external shocks as zombie companies. In order to exclude these companies, we add the fourth condition. It can be said that if a company meets the above four conditions at the same time, it can be considered as a zombie company to a large extent.

Table 5 reports the corresponding estimation results by gradually adding control variables. Column (1) does not include any control variables nor does it control the fixed effects of industry, city, and year. The estimated coefficient of the reform of administrative examination and approval (AEASR) is -0.0326 , and it has passed the $1 \%$ significance test. However, it can only be inferred that there is a negative correlation between the reform of administrative approval and the formation of zombie companies. The conclusion of causality needs to be further controlled by relevant variables. 
TABLE 5: Regression results of the inhibitory effect of the reform of administrative examination and approval on zombie companies.

\begin{tabular}{lccc}
\hline & $(1)$ & $(2)$ & $(3)$ \\
\hline \multirow{2}{*}{ AEASR } & $-0.0326^{* * *}$ & $-0.0081^{* * *}$ & $-0.0072^{* * *}$ \\
& $(0.0013)$ & $(0.0024)$ & $(0.0024)$ \\
FC & & & 0.0001 \\
& & & $(0.0001)$ \\
SC & & & $0.0000^{* * *}$ \\
& & & $(0.0000)$ \\
Export & & & $0.0114^{* * *}$ \\
& & & $(0.0035)$ \\
Subsidy & & & $0.0614^{* * *}$ \\
& & & $(0.0229)$ \\
FIE & & & $-0.0535^{* * *}$ \\
& & & $(0.0031)$ \\
HHI & & & $\left(0.0279^{* * *}\right.$ \\
& & & \\
Industry fixed effect & No & Control & Control \\
City fixed effect & No & Control & Control \\
Year fixed effect & No & Control & Control \\
\hline Pseudo goodness of fit & 0.004 & 0.064 & 0.067 \\
Sample size & 151855 & 151855 & 151190 \\
\hline
\end{tabular}

Note. Symbols ${ }^{*},{ }^{* *},{ }^{* * *}$ represent the significance level of $10 \%, 5 \%$, and $1 \%$ respectively; the values in parentheses are the robust standard deviations.

On the basis of column (1), column (2) further controls the fixed effects of industry, city, and year. The estimated coefficient of the reform of administrative examination and approval is -0.0081 , and it is significant at the $1 \%$ significance level. Compared with the estimated results in column (1), the inhibitory effect of the reform of administrative examination and approval on the formation of zombie companies is reduced. Therefore, omitting important explanatory variables will overestimate the policy effect of the reform of administrative examination and approval. On the basis of column (2), column (3) adds control variables such as fixed costs, sunk costs, proportion of exports, proportion of subsidies, proportion of foreign-funded enterprises, and degree of market competition. When these variables are controlled, the estimated coefficient of the reform of administrative examination and approval is significantly negative; compared with column (2), the difference of coefficient size is small. According to the estimation results in Table 5, it can be seen that in cities where administrative approval centers have been established, companies are less likely to become zombie companies. Therefore, it can be considered that the reform of administrative examination and approval has inhibited the formation of zombie companies, which indicates that the reform of administrative examination and approval can improve the efficiency of resource allocation.

\section{Research Conclusions}

The reform of the administrative examination and approval system is an important governmental approach aimed at easing regulations and reducing government intervention.
The concept of the reform is centered on optimizing the examination and approval procedure, so as to increase the efficiency of the administrative examination and approval system and to reduce the institutional transaction costs of enterprises. Based on the views of the degree of productivity dispersion, this study utilized the data of the time of establishment of administrative examination and approval centers in each administrative division in China, as well as data from the China Industry Business Performance Database from 1998 to 2007 to empirically determine whether the reform of the administrative examination and approval system was able to improve the efficiency of resource allocation. The empirical results show that the reform was beneficial for reducing the degree of productivity dispersion among enterprises and was able to improve the efficiency of resource allocation. This conclusion was further supported by a series of robustness tests which included a treatment of endogeneity, a regression analysis for different industries, a remeasured efficiency of resource allocation regression, and a placebo test. Furthermore, this study examined the heterogeneity of the effects of the reform on the efficiency of resource allocation for industries with different market entry and exit rates. The results revealed that the reform was able to reduce the degree of productivity dispersion among the enterprises in industries with lower entry rates, thereby increasing the efficiency of resource allocation, whereas this effect was less prominent for industries with higher entry rates. On the other hand, the positive effects of the reform on the efficiency of resource allocation are more prominent in industries with low exit rates, while the effects were less prominent in industries with high exit rates.

\section{Data Availability}

The data used in this study were obtained from the China Industry Business Performance Database from 1998 to 2007 and the time of establishment of the administrative examination and approval center in each administrative division in China.

\section{Conflicts of Interest}

The authors declare that they have no conflicts of interest.

\section{Authors' Contributions}

Y. Z. and L. Z. conceptualized the study; L. Z. and Y. Z. developed methodology; L. Z. provided software; Y. Z. performed formal analysis; Y. Z. and L. Z provided the resources; Y. Z, Y. Z., and L. Z wrote and prepared original draft; Y. Z., Y. Z., and L. Z. wrote, reviewed, and edited the article; L. Z. and Y. Z. supervised the study; L. Z. was responsible for project administration; all authors have read and agreed to the published version of the manuscript.

\section{Acknowledgments}

This study was funded by the Humanity and Social Science Youth Foundation of Ministry of Education of China, under project number. 18XJC790020. 


\section{References}

[1] E. Bartelsman, J. Haltiwanger, and S. Scarpetta, "Crosscountry differences in productivity: the role of allocation and selection," American Economic Review, vol. 103, no. 1, pp. 305-334, 2013.

[2] C.-T. Hsieh and P. J. Klenow, "Misallocation and manufacturing TFP in China and India," Quarterly Journal of Economics, vol. 124, no. 4, pp. 1403-1448, 2009.

[3] D. Restuccia and R. Rogerson, "Policy distortions and aggregate productivity with heterogeneous establishments," Review of Economic Dynamics, vol. 11, no. 4, pp. 707-720, 2008.

[4] B. Jovanovic and P. K. Goldberg, "Misallocation and growth," American Economic Review, vol. 104, no. 4, pp. 1149-1171, 2014.

[5] C. Syverson, "What determines productivity?" Journal of Economic Literature, vol. 49, no. 2, pp. 326-365, 2011.

[6] J. M. Arnold, G. Nicoletti, and S. Scarpetta, "Regulation, resource reallocation and productivity growth," European Investment Bank Papers, vol. 16, pp. 90-115, 2011.

[7] L. Brandt, J. Van Biesebroeck, and Y. Zhang, "Creative accounting or creative destruction? Firm-level productivity growth in Chinese manufacturing," Journal of Development Economics, vol. 97, no. 2, pp. 339-351, 2012.

[8] D. Dollar and S. Wei, "Das (wasted) kapital: firm ownership and investment efficiency in China," NBER Working Paper, 2007.

[9] A. C. Pigou, The Economics of Welfare, Macmillan and Co, London, UK, 1938.

[10] S. Peltzman, "Toward a more general theory of regulation," The Journal of Law and Economics, vol. 19, pp. 245-248, 1976.

[11] R. A. Posner, "The social costs of monopoly and regulation," Journal of Political Economy, vol. 83, no. 4, pp. 807-827, 1975.

[12] G. J. Stigler, "The theory of economic regulation," The Bell Journal of Economics and Management Science, vol. 2, no. 1, pp. 3-21, 1971.

[13] H. De Soto, The Other Path: The Invisible Revolution in the Third World, Harper and Row, New York, NY, USA, 1989.

[14] S. Djankov, R. La Porta, F. Lopez-de-Silanes, and A. Shleifer, "The regulation of entry," The Quarterly Journal of Economics, vol. 117, no. 1, pp. 1-37, 2002.

[15] L. Branstetter, F. Lima, L. J. Taylor, and A. Venâncio, "Do entry regulations deter entrepreneurship and job creation? Evidence from recent reforms in Portugal," The Economic Journal, vol. 124, no. 577, pp. 805-832, 2014.

[16] M. Bruhn, "License to sell: the effect of business registration reform on entrepreneurial activity in Mexico," Review of Economics and Statistics, vol. 93, no. 1, pp. 382-386, 2011.

[17] D. S. Kaplan, E. Piedra, and E. Seira, "Entry regulation and business start-ups: evidence from Mexico," Journal of Public Economics, vol. 95, pp. 1501-1515, 2001.

[18] D. Rostam-Afschar, "Entry regulation and entrepreneurship: a natural experiment in German craftsmanship," Empirical Economics, vol. 47, no. 3, pp. 1067-1101, 2014.

[19] F. Schivardi and E. Viviano, "Entry barriers in retail trade," The Economic Journal, vol. 121, no. 551, pp. 145-170, 2011.

[20] S. E. Black and P. E. Strahan, "Entrepreneurship and bank credit availability," The Journal of Finance, vol. 57, no. 6, pp. 2807-2833, 2002.

[21] S.-H. Lee, Y. Yamakawa, M. W. Peng, and J. B. Barney, "How do bankruptcy laws affect entrepreneurship development around the world?" Journal of Business Venturing, vol. 26, no. 5, pp. 505-520, 2011.
[22] K. Nystrom, "The institutions of economic freedom and entrepreneurship: evidence from panel data," Public Choice, vol. 136, no. 3-4, pp. 269-282, 2008.

[23] B. Casu, B. Deng, and A. Ferrari, "Post-crisis regulatory reforms and bank performance: lessons from asia," European Journal of Finance, vol. 23, pp. 1-28, 2016.

[24] A. Guerrini, M. Molinos, and G. Romano, Italian Regulatory Reform and Water Utility Performance: An Impact Analysis, Utilities Policy S0957178717302023, 2018.

[25] N. Balasubramanian and J. Sivadasan, "Capital resalability, productivity dispersion, and market structure," Review of Economics and Statistics, vol. 91, no. 3, pp. 547-557, 2009.

[26] N. Guner, G. Ventura, and Y. Xu, "Macroeconomic implications of size-dependent policies," Review of Economic Dynamics, vol. 11, no. 4, pp. 721-744, 2008.

[27] S. Ding, W. Jiang, and P. Sun, "Import competition, dynamic resource allocation and productivity dispersion: micro-level evidence from China," Oxford Economic Papers, vol. 68, no. 4, pp. 994-1015, 2016.

[28] K. Desmet and E. Rossi-Hansberg, "Urban accounting and welfare," American Economic Review, vol. 103, no. 6, pp. 2296-2327, 2013.

[29] C. T. Hsieh and E. Moretti, "Housing constraints and spatial misallocation," CEPR Discussion Papers, 2018.

[30] P. D. Fajgelbaum, E. Morales, J. C. Sua'rez Serrato et al., "State taxes and spatial misallocation," The Review of Economic Studies, vol. 86, pp. 333-376, 2018.

[31] L. Foster, J. Haltiwanger, and C. J. Krizan, "Market selection, reallocation, and restructuring in the U.S. Retail trade sector in the 1990s," Review of Economics and Statistics, vol. 88, no. 4, pp. 748-758, 2006.

[32] L. Liu, "Entry-exit, learning, and productivity change Evidence from Chile," Journal of Development Economics, vol. 42, no. 2, pp. 217-242, 1993.

[33] R. J. Caballero, T. Hoshi, and A. K. Kashyap, "Zombie lending and depressed restructuring in Japan," American Economic Review, vol. 98, no. 5, pp. 1943-1977, 2008.

[34] M. A. Mcgowan, A. Dan, and V. Millot, "The walking dead ?: zombie firms and productivity performance in OECD countries," OECD Economics Department Working Papers, 2017.

[35] S.-I. Fukuda and J.-I. Nakamura, "Why did 'zombie' firms recover in Japan?" The World Economy, vol. 34, no. 7, pp. 1124-1137, 2011.

[36] M. Storz, M. Koetter, R. Setzer et al., "Do we want these two to tango? On zombie firms and stressed banks in europe," IWH Discussion Papers, 2017.

[37] L. Brandt, T. Tombe, and X. Zhu, "Factor market distortions across time, space and sectors in China," Review of Economic Dynamics, vol. 16, no. 1, pp. 39-58, 2013.

[38] J. Lu and Z. Tao, "Trends and determinants of China's industrial agglomeration," Journal of Urban Economics, vol. 65, no. 2, pp. 167-180, 2009.

[39] M. Bertrand, E. Duflo, and S. Mullainathan, "How much should we trust differences-in-differences estimates?" The Quarterly Journal of Economics, vol. 119, no. 1, pp. 249-275, 2004.

[40] M. J. Melitz, "The impact of trade on intra-industry reallocations and aggregate industry productivity," Econometrica, vol. 71, no. 6, pp. 1695-1725, 2003.

[41] G. S. Olley and A. Pakes, "The dynamics of productivity in the telecommunications equipment industry," Econometrica, vol. 64, no. 6, pp. 1263-1297, 1996.

[42] X. Zhu and Y. Zhang, "Political mobility and dynamic diffusion of innovation: the spread of municipal pro-business 
administrative reform in China," Journal of Public Administration Research and Theory, vol. 26, no. 3, pp. 535-551, 2016.

[43] H. A. Hopenhayn, "Entry, exit, and firm dynamics in long run equilibrium," Econometrica, vol. 60, no. 5, pp. 1127-1150, 1992.

[44] C. Syverson, "Product substitutability and productivity dispersion," Review of Economics and Statistics, vol. 86, no. 2, pp. 534-550, 2004.

[45] Z. Song, K. Storesletten, and F. Zilibotti, "Growing like China," American Economic Review, vol. 101, no. 1, pp. 196-233, 2011.

[46] J. Levinsohn and A. Petrin, "Estimating production functions using inputs to control for unobservables," Review of Economic Studies, vol. 70, no. 2, pp. 317-341, 2003. 